\title{
NEW DEVELOPMENT OF PROPORTIONAL CARTRIDGE VALVE TECHNIQUE IN RECENT YEARS
}

\author{
Lu Yong Xiang \\ Zhejiang University \\ Hangzhou, China
}

\section{ABSTRACT}

The development in the cartridge and proportional techniques may be one of the most important affairs in hydraulic control field within last 20 years. The background of it is demonstrated in the paper, especially the combination of proportional technique with cartridge technique in recent years. An analysis and synthesis of their constructional principles are given. The trend of development of them are also forecasted in the paper.

\section{KEYWORDS}

Cartridge valve

Proportional technique

Development

\section{BACKGROUND OF THE DEVELOPMENTS}

The cartridge and proportional techniques may be the most important development in field of hydraulic control in recent years. Although their history of development is less than 20 years, but those techniques have been ripened day after day, and found more and more applications in practical engineering. The speed of its development makes one surprised due to a profound background of engineering technology .

Since late 60 's, the scale of production and power of machine have been larger and larger so that flowrate in hydraulic systems has risen greatly, in some cases they are more than $500 \mathrm{l} / \mathrm{min}$. On the other hand, a traditional direction-control valve was a spool valve with four-throttling orifices, thus great pressure drop in the valve exists and furthermore the switching velocity is limited due to the large mass of its spool and long overlap in axis direction; such a valve was usually constructed in sub-plate or flange-mounting form, so the valve-block was heave and costs more mounting space. Moreover, bigger and longer spool, for large flowrate control, needs greater clearance in diameter, so the leakage in valve increases remarkably. Thus it is reasonable to try to find a new construction of control valve which can be made better use in engineering control systems where higher pressure and larger flowrate are necessary. This do is the background of appearance and rapid development of 2-way-cartridge technique since early $70^{\prime}$ s.

The essential idea about 2-way-cartridge valve is to decompose a traditional multithrottling edges valve into several single-throttling orifices, each of them can be used as a basic control unit. In a cartridge valve, the construction of its power stage is designed as standard cartridge-units which can be inserted into an assembly seat in a valve-block which possesses control bores according to the system circuit. By use of different cover and pilot valve which have the same size for mounting, many hydraulic control systems with different functions are composed.

Figure 1 shows the general construction of a cartridge valve. It consists of four main parties: a pilot valve, a cover, a cartridge-unit (include a sleeve and a piston ) and an assembly seat. It usually have an input port "A", an output port "B" and a control port " $\mathrm{X}$ ". The assembly seat is so designed that it can be manufactured with a combined tool and makes it possible to insert a cartridge-unit into it in one direction. Now, there is an international standard (DIN 24342) for size-series of cartridge valves. So far, there are three typical kinds of cover and cartridge-unit, as is shown in fig. 2. The selection between them is based on the manufacture condition and the cost. A cover is used not only for sealing and mounting the cartridge-unit but also for connecting the car- 

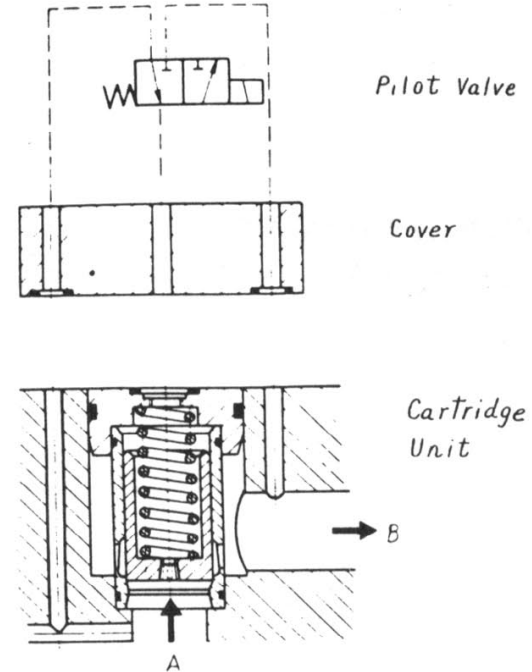

Fig. 1 construction of cartridge valve

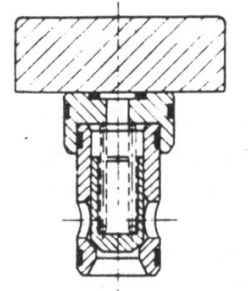

(a)

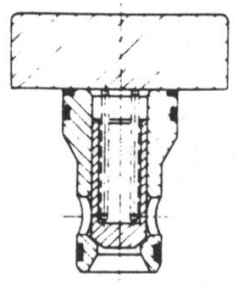

( b )

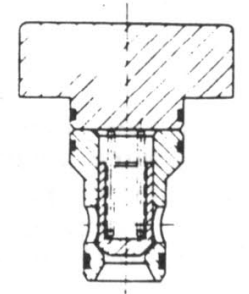

(c)
Fig.2 covers and cartridge-units

tridge-unit with the pilot valve, so it has several bores to achieve the given functions. Adjusting handles, sensors, pilot valves or other elements can also be mounted on the cover, only if their mounting size is in keeping with the international standards for general-components such as CETOP or ISO (see fig. 3). A cartridge-

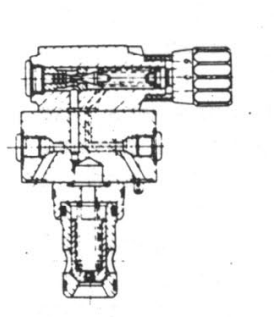

(a)

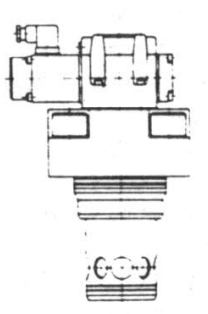

(b)

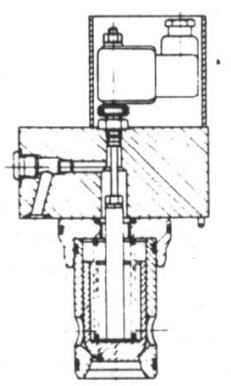

(c)
Fig. 3 elements mounted on the cover

unit consists of a sleeve, a movable piston, a spring to held the piston and sealing elements. Two types of general cartridge-unit are shown in figure 4, the first one is a seat valve and the other is

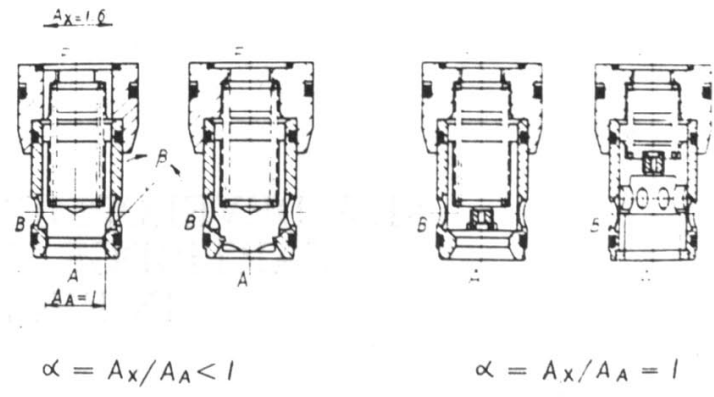

Fig.4 Two types of general cartridge-unit

slide valve. The combination of them also appears in recent years. The control area ratio of a seat valve can be specified as:

$$
\alpha_{A}=\frac{A_{A}}{A_{\mathbf{X}}}
$$

$\alpha_{A}$ is a very important parameter to the characteristics of a cartridge valve. For switch valve, it lies between 0.5 to 1.0 and for pressure or flowrate-regulation valve, it lies between 0.8 to 1.0 . The conical angle affects the gain of discharge area significantly, and it lies generally between $18^{\circ}$ to $45^{\circ}$. According to the well known flow-law, flowrate through a throttle orifice of a valve is:

$\mathrm{Q}=\alpha_{D}(\operatorname{Re}) \cdot \mathrm{A}(\mathrm{x}) \cdot \sqrt{\frac{2}{\rho}} \cdot \sqrt{\mathrm{P}_{\mathrm{A}}-\mathrm{P}_{\mathrm{B}}} \cdot \operatorname{Sign}\left(\mathrm{P}_{\mathrm{A}}-\mathrm{P}_{\mathrm{B}}\right)$

Where, the discharge coefficient $\alpha_{D}(\operatorname{Re})$ can be described as a function of Reynolds Number. Test by the author reveals that is affected by the port shape of the valve and is determined as:

$$
D= \begin{cases}K_{\propto D} \cdot \sqrt{\operatorname{Re}}, & \text { when } \operatorname{Re} \leqslant \operatorname{Re}_{G} \\ \alpha_{D \max } & \text { when } \operatorname{Re}>\operatorname{Re}_{G}\end{cases}
$$

Figure 5 illustrates $K_{\alpha D}$ and $\alpha_{D \max }$ of var-

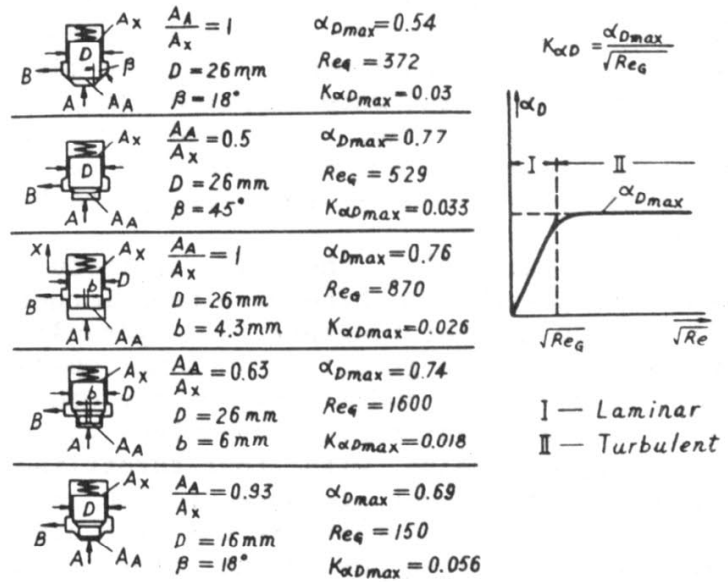

Fig.5 and of various orifices 
ious shapes of valve' throttling orifice.

The flow-force of a cartridge valve always in the direction to close the valve. The amount of it is depend on the pressure difference over the orifice and the shape of the valve' throttling orifice. Confirmed by an experiment (Fig. 6), the X-F curve (displacement of valve to flow-force) has two different areas, as is shown in figure 6. In the constant-pressure area "A", the flow-force is proportional to the displacement of the valve (by rectangular thrott1ing window):

$\mathrm{F}_{f}=-\mathrm{K}_{f} \cdot\left|\mathrm{Pa}-\mathrm{P}_{b}\right| \cdot \mathrm{X}$

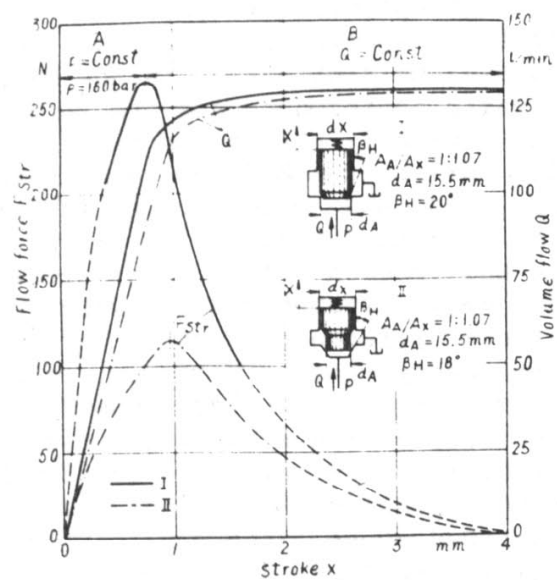

Fig.6 X-F curve of flow-force

where $K_{f}$ represents flow-force coefficient, which is affected by the shape and scale of a valve and must be determined by experiments.

With a given pressure difference, the flow force will be maximum if the flowrate reaches, by increment of the displacement of the valve, the pump-supplying flowrate and the force will remain in this value even if the displacement of valve is continue to increase. In this case, the force curve is in the second area - constant flowrate area "B". A switching valve works in both areas, while a regulation valve can only work in area "A".

The maximum throttling area is usually determined with consideration of the limited velocity of discharge $(5-20 \mathrm{~m} / \mathrm{s}$, lower value for switching valve and higher value for regulation valve) while the valve is in rated flowrate.

Compared with conventional valves, cartridge valves have many advantages in construction, characteristics, manufacture

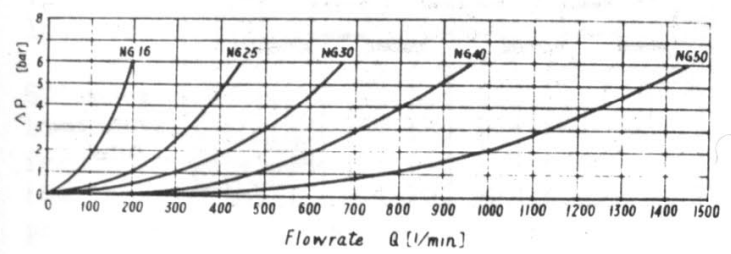

Fig.7 flow performance of cartridge valves cost, insensitivity to dirty of oil, maintenance, adjustment and so on.

--- Flow can pass unimpededly through a cartridge valve due to broad passageways and little corner turns, so a cartridge valve has a lower pressure drop. Figure 7 is the flow characteristics for series of cartridge valves. So it is clear that cartridge valves are suitable to great flowrate systems.

--- A cartridge valve has low leakage and is energy-saving because a seat valve is used and its construction allows a small clearance.

-- The dynamic performance of a cartridge valve is good since its mass is small.

--- A 2-way-cartridge valve can implement many functions only if various pilot circuits are employed; and this causes its construction simpler than that of traditional one.
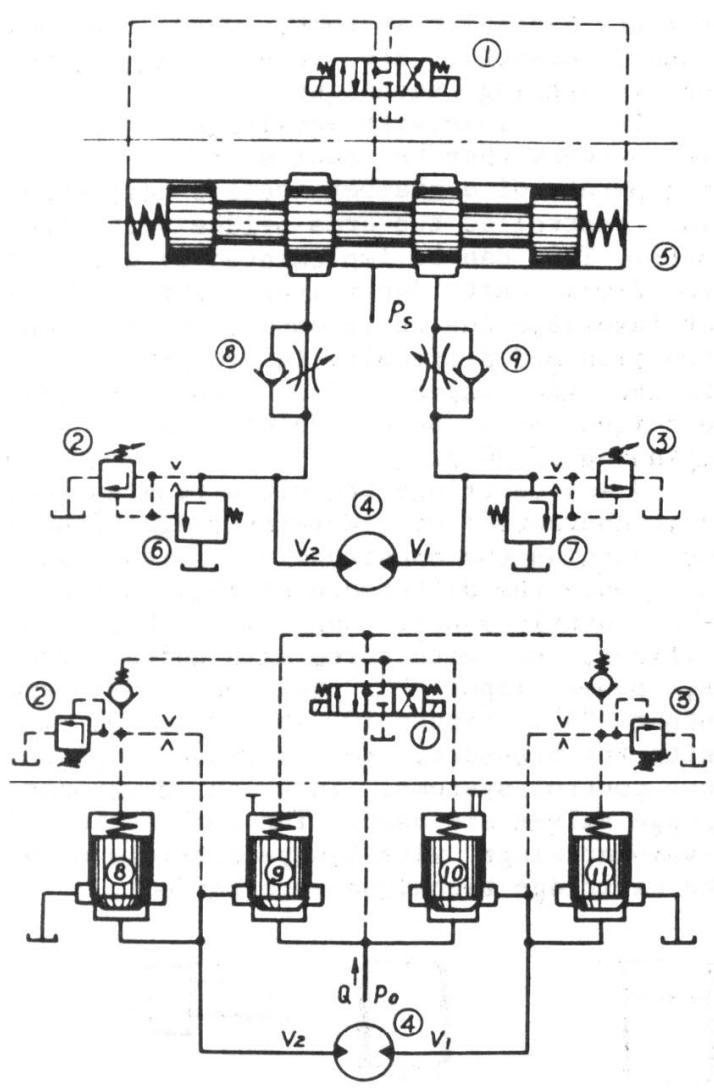

Fig. 8 velocity control systems for motor

Figure 8 illustrates two velocity control systems for a hydraulic motor, in the first one traditional valves are used in which two relief valves are necessary for both rotation directions, in the second one cartridge valves are used where only several pilot valves for direction, pressure or throttling control are necessary. Therefore, the power control circuit is remarkably simplified. The greater the control power is and the more complex the system is, the more significant advantage of the systems with cartridge valves is (see Fig.9). Nowadays, most of the high 


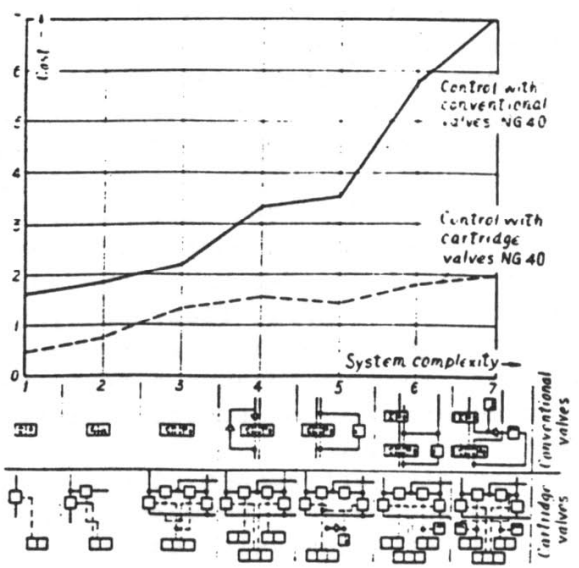

Fig.9 Comparison of system with cartrige and traditional valve

pressure hydraulic systems, whose nominal channel diameter are larger than $32 \mathrm{~mm}$, employ cartridge technique.

It is clear with knowledge of hydraulic network that to control the pressure or flowrate of a chamber needs a differential controlled two arms bridge with three ports. This can be implemented by using of two 2-way-cartridge valves, but this is not favorable due to incompactness in construction and difficulty in synchronization of the two valves. So, 3-way-cartridge technique have been developed since the beginning of 80 's.

3-way-cartridge technique remains some basic characters of 2-way-cartridge technique such as the construction of its seat. What only the difference of them is that a 3-way-cartridge-unit has two throttling orifices, so with three main ports, that is, power input " $\mathrm{P}$ ", tank port " $\mathrm{T}$ " and output "A". Figure 10 shows control circuits for pressure, velocity and displacement control systems, in which 3-way-cartridge valves are used. The combination of 2-way-cartridge with 3-way-cartridge makes the cartridge technique more perfect.

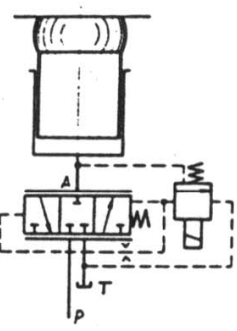

Pressure Control
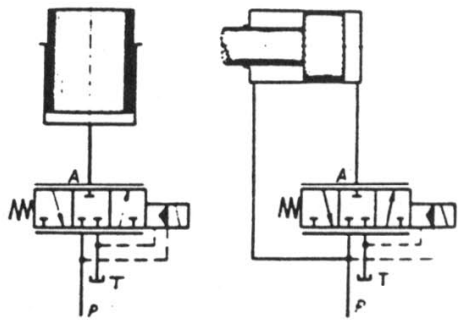

Velocity and displacemont Cenirel
Fig.10 pressure, velocity and displacement control systems

The development of science and technology after $60^{\prime}$ 's makes it possible to give full study on industry processes and to get an accurate optimization-object of their controllers. This reveals that it is the continuous instead of switch real-time control that can meet high requirements of practical applications. In order to implement the control for great-power of large scale production device, engineers try to find a reliable, low-cost, high-robust and effective electro-hydraulic control strategy. With such a strategy, the results and advantages of both electronics and fluid power technique are combined, and then satisfy control requirements of engineering devices. This is the background of the development in electro-hydraulic proportional control technique.

In fact, at the beginning of 50 's, engineers successfuly developed electrohydraulic servo valves for high-frequency control of jet-plane. At that time, it might be for a special purpose that engineers focused their attention in how to get higher dynamic performance and precision. A servo valve usually has to use two stages due to its low-power E-M (electro-mechanic) convertor, and the pilot stage is very sensitive to dirty of oil. For rising of its gain and frequency band, an electrohydraulic servo system has to work with high pressure difference about 70 bar, this causes more energy-lose. Moreover, for an ideal characteristics on "zero zone", the spool and sleeve of a servo valve must be made in a high precision. So a servo valve is relative expensive. Because of the drawbacks described above, the applications of servo valve are limited in a few fields where high control performances or better technique condition are necessary. Nevertheless, proportional technique arms at meeting most open-loop or closed-loop control demands of general engineering equipment. Thus its development should follow a new technical philosophy, that is to say, static and dynamic behaviors, efficiency, robustness, reliability and cost should be comprehensively considered. Upon to now, the proportional technique has its history only about 20 years, which can be divided into two steps. The first ten years is an advancing period and the second is ripening period. On the other hand, a proportional valve lies between a traditional valve and a servo valve, so it was developed from both sides. Figure 11 shows a cross section of an electro-hydraulic pro-

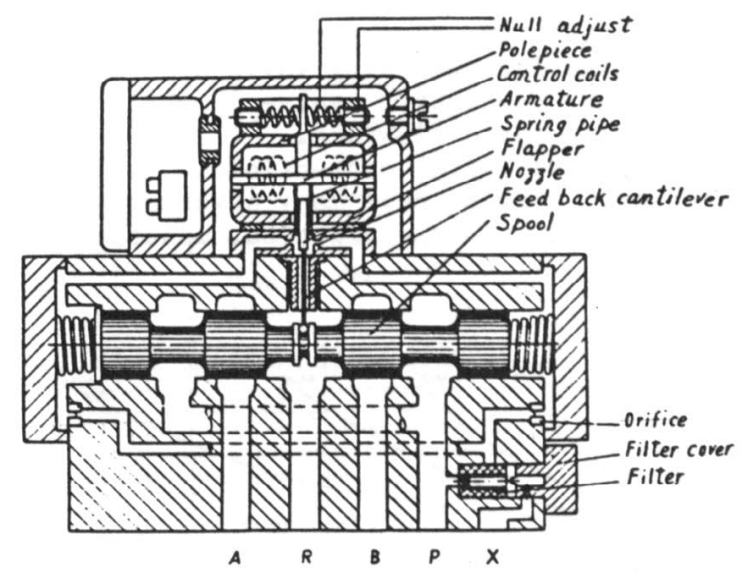

Fig.11 An proportional valve (Moog) 
portional valve made by Moog Company, it is very close to a servo valve except in the following aspects:

--- Simplification of the configurations of dry force motor and spring-tube.

-- 10-15\% dead-band of nu11 position.

--- Lower pressure drop (about 10 bar).

--- Full round throttling window without sleave for large-scale-valves.

--- Standard mounting plate $($ DIN24340 = ISO 4401)

The other style of proportional valves are developed from conventional regulationvalves by use of solenoids to replace the regulation handles. The typical example is the proportional pressure and flow regulation valves developed by Yuke Company, which have advantages of low-cost, exchangeable to traditional valves. But their characteristics is usually unsatisfied due to a big hysteresis $(\leqslant 7 \%)$ and a low frequency band $(\leqslant 1-3 \mathrm{~Hz})$.

At the beginning of $70^{\prime} \mathrm{s}$, the most typical direction control valve should be Type KL valve developed by a Swiss company. A pear of pressure reducing valves are used as pilot stage whose output pressures are proportional to the input current of their own solenoid. The main stage of $4 \mathrm{way}-\mathrm{spool}$ centered by two springs. The pilot control pressure drives the spool to a given position where the pressure-force is equal to the spring-force. Except for its throttling orifice, the construction of such valve is almost the same as a conventional valve and it possessed all characters of electrohydraulic valve (see figure 12). Therefore, it is still in production till now.

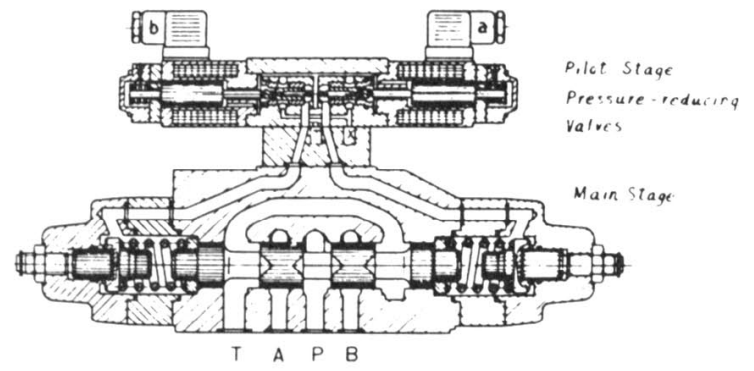

Fig.12 Proportional direction valve

In the middle of $70^{\prime} \mathrm{s}$, one of the most important developments of electro-hydraulic proportional technique might be the application of proportional solenoid and displacement sensor, both are high-pressureresistant. The former provides a reliable, low-cost E-M convertor with enough stroke and driving force for proportional valve. The latter is necessary to realize closedloop control of a proportional valve. At the end of 70's and beginning of 80 's, proportional technique began to combine with cartridge technique and various feedback methods were used. As a result, the static and dynamic performances of proportional valves were improved continuously and their output power was extended again and again. So led to more and more applications of them. A statistics by VDMA in 1986 showed that the turnout of proportional and servo valves made in hest Germany were $40 \%$ of that of total solenoid valves, this percent was eight times as in 1980 (Fig. 13).
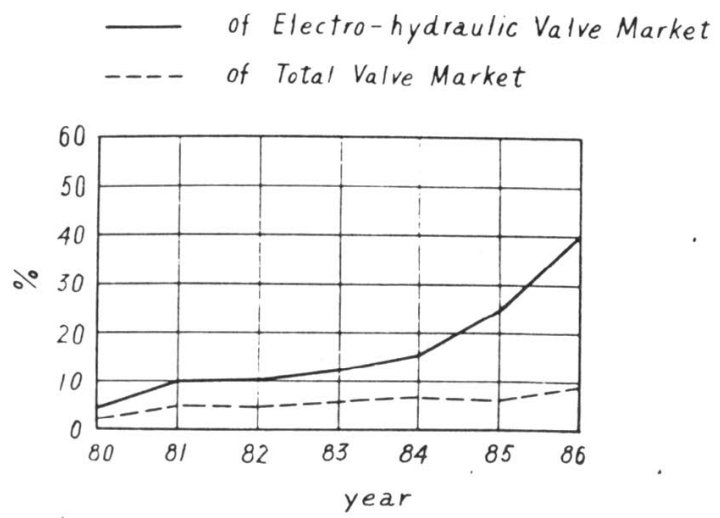

Fig.13 turnout of proportional, servo valves and total solenoid valves
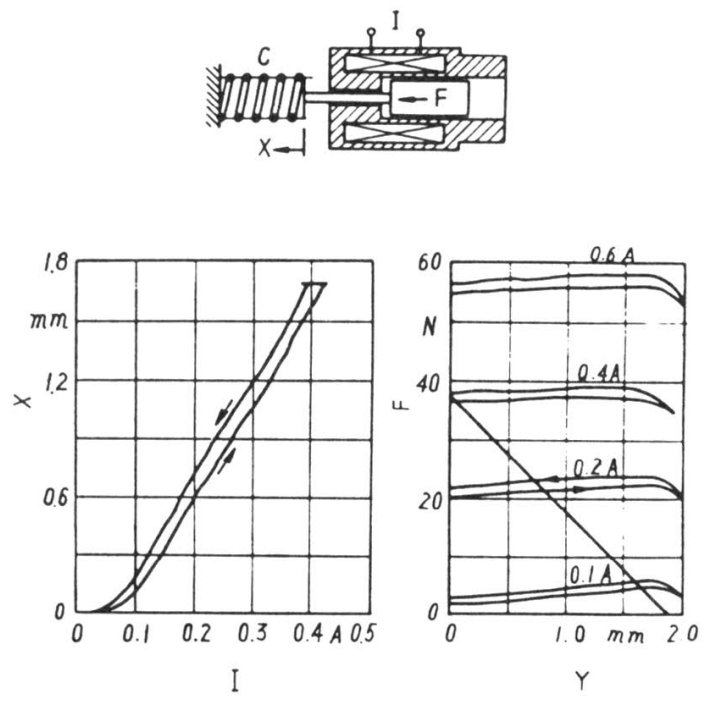

(a)
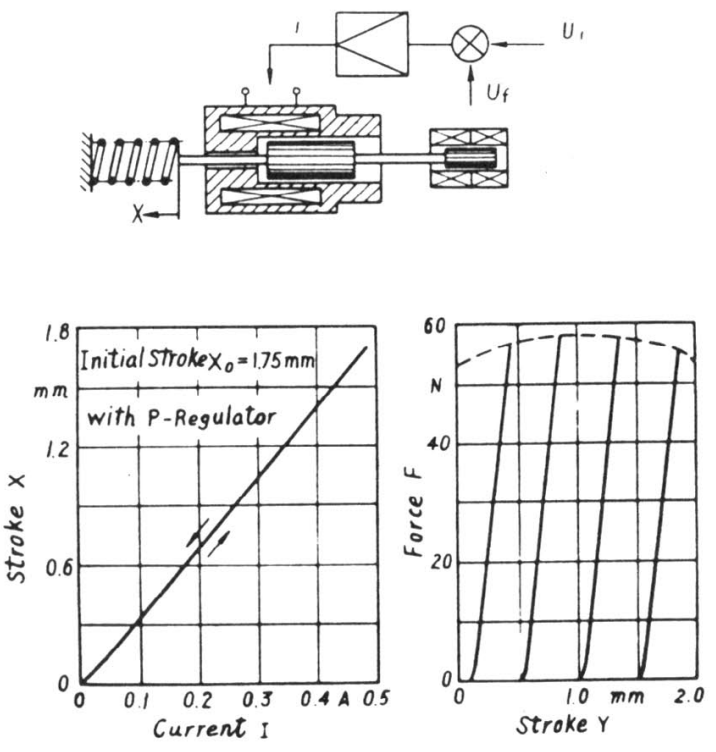

(b)

Fig.14 proportional solenoid 
NEW DEVELOPMENT OF CARTRIDGE PROPORTIONAL TECHNIQUE

Since the beginning of $80^{\prime} \mathrm{s}$, the main new developments of cartridge proportional technique may be in two aspects: improvement of E-M convertor including its electronic amplifier and achievement in internal feedback units.

Favorable performance was then got and proportional technique went into its ripening period.

\section{Electro-Mechanical Convertor}

Combined with spring, a high-pressureresistant proportional solenoid can get a current-displacement linear character, due to its current-force linear character and horizontal force-displacement character. But such a component is not good in antidisturbances of friction, its stiffness is low and its linearity or hysteresis is not satisfied (see figure 14a). So, a proportional solenoid with displacement sensor has been developed, its linearity and stiffness are then improved remarkably (figure 14b). The proportional valves with such solenoids have much better control precision even if large disturbances exist. This is the key answer to why the proportional valves with electro-feedback have found wide applications since 80 's.

What is necessary to point out is that in IHP, Aachen of West Germany, successfuly developed a solenoid with horizontal displacement-force character from a general on-off solenoid by use of a special electronic regulator in 1986. This work made it possible to use a switch solenoid as a proportional E-M convertor (see figure 15, 16).

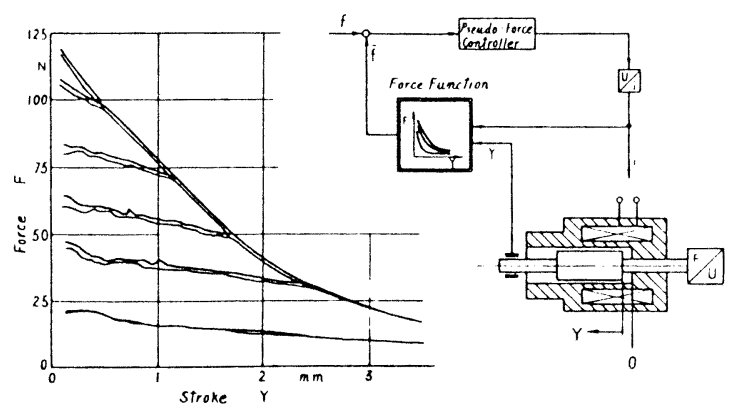

Fig.15 E-M convertor (IHP)

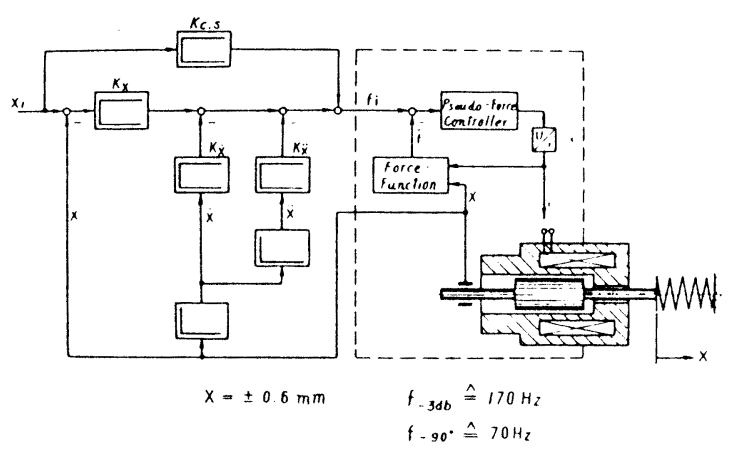

Fig.16 E-M convertor (IHP)
As is well known, all of the electronic amplifier for proportional solenoid utilize a current-feedback circuit. But current-feedback is effective only to jumpup speed not to jump-down speed of coilcurrent. A new amplifier with double poles power-regulation circuit appeared recently, which makes a solenoid had a similar jumpdown current speed as its up current speed, and then remarkably broaden the frequencyband of the solenoid (see figure 17). On the other hand, the magnetic eddy current of a solenoid is decreased and then its dynamic characteristics is improved by making use of high-resistant silicon iron.

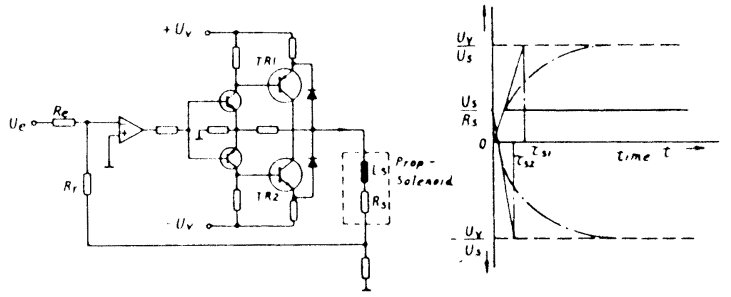

Fig. 17 amplifier with bipole circuit

For a 3-way cartridge valve, FPTC (Institute for Fluid Power Transmission and Control) of Zhejiang University have developed a bipole-proportional solenoid, which have a pair of stimulating coils and a pair of control coils. Supplying by a constantcurrent resource, the stimulating coils is independent to the control coils. Utilizing the non-linearity of magnet material, the gain of control characteristics can be changed by adjusting the stimulating current. The bipole proportional solenoid has a better linear and dynamic characteristics than those of single-pole one (see fig. 18).

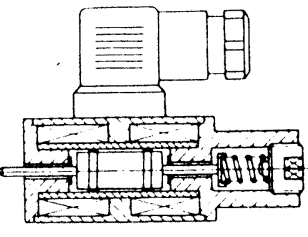

Construction

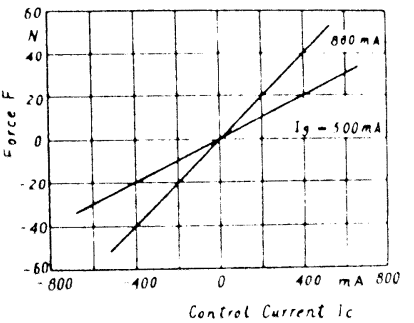

$f_{-3 d b}-110 \mathrm{~Hz}_{2} \quad f_{.90^{\circ}}-170 \mathrm{~Hz}$ by $+25 \% \mathrm{Ia}$
Fig.18 bipole-proportional solenoid

Proportional pressure control

In the early period of the development of proportional pressure valve, man developed the pilot stages which matched common proportional solenoids. For example, a small poppet valve, a displacement-force feedback regulator with a displacement sensor or a flapper-nozzle pilot stage were constructed (Fig. 19a-c). To improve the damping, the poppet valve can be designed as a damping-plug (Fig. 19d). And the main stage can reach a higher dynamic damping 
(a)

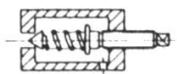

(s)
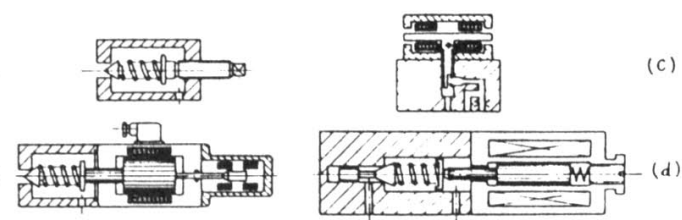

Fig. 19 Pilot stages for pressure valve

when the resistance network is improved by means of shifting the static working-point of hydraulic semi-bridge to a higher pressure-flowrate gradient zone, for the curve of flowrate-pressure is parabolic (Fig. 20).

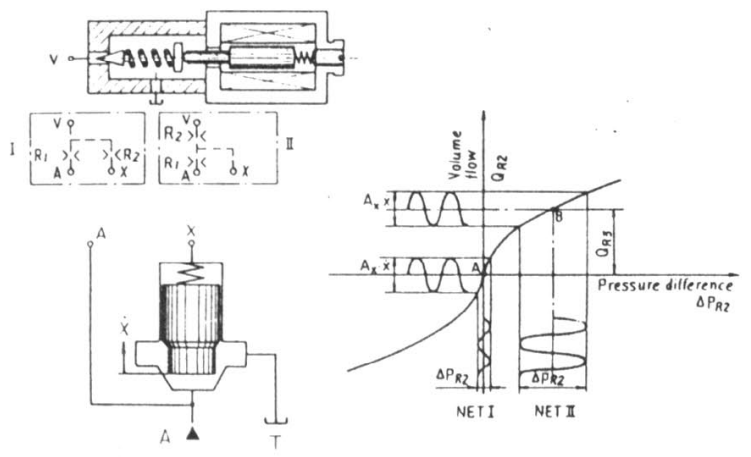

Fig.20 Principle for higher dynamic damping

In general pilot-operated cartridge pressure control valve, the feedbackpressure detected by the pilot stage is that in the controlled chamber of main stage, not its output pressure. So the interference of flow-force in the main stage will sharp rise the tolerance of the regulating pressure when the given pressure and flowrate increases.

The method with the principle of the system pressure directly detecting and the feedback is accepted in a new proportional pressure valve developed by FPTC, and the pressure control accuracy has been improved considerably (Fig. 21). The new valve with two-stage spools, utilizes dynamic pressure feedback between the pilot and main stages, so that the stability of the valve can been improved remarkably.

The main development in a proportional pressure reducing valve is that its pilot valve detects the pressure at output port directly and the the supplying oil for

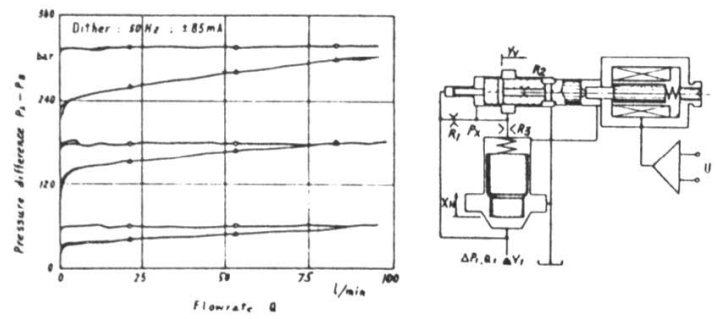

Fig.21 Proportional pressure valve (FPTC) pilot valve can be introduced from the input port of the valve. With this new concept a better dynamic performance and a lower minimum controllable pressure can be achieved (Fig. 22).

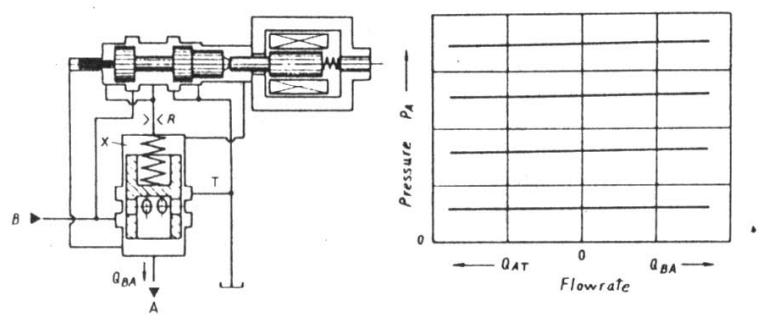

Fig. 22 proportional pressure reducing valve

The other achievement is that the 3way-cartridge proportional pressure reducing valve is developed. It is the new valve's main advantage that it's flowpressure characteristics can be expanded to the second quadrant, that is to say, the pressure is controllable no matter how much the flowrate is, zero, positive or negative. Such a valve is suitable to a spring load or an inertia load. Figure 23 shows a 3-way-cartridge proportional pressure reducing valve and its characteristics. Other experiment reveals that the step response time of such a valve to nominal output is less than $20 \mathrm{~ms}$.
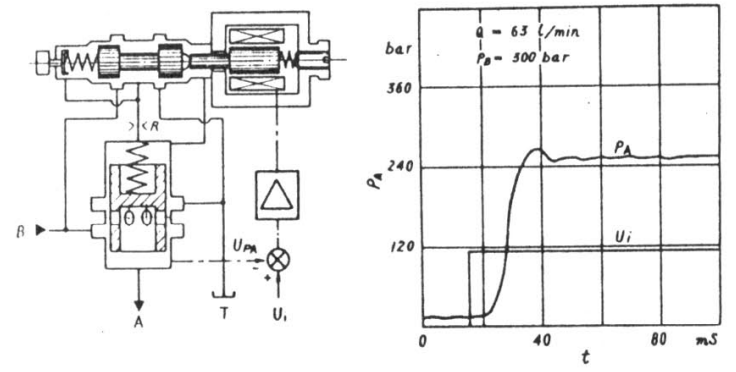

Fig.23 3-way-cartridge proportional pressure reducing valve

\section{Proportional throttling}

Besides the spring force and friction, on the spool of proportional throttle is acted a flow force, which is proportional to the flowrate and the square root of the pressure difference. therefore the nominal size of the single stage proportional throttling valve with a electrical displacement feedback is limited below $16 \mathrm{~mm}$. The throttling valve for the large flowrate and the high pressure must be the pilotoperated style as is shown in Fig. $24 \mathrm{a}$.

Up to the date, the common construction of a pilot proportional throttling valve is of displacement-electro-feedback or displacement-force-feedback (Fig. $24 \mathrm{~b}, \mathrm{c})$. The super-scale valve can be constructed as three staged (Fig. 25). The valve consists of a 4-way pilot spool valve, a controlled piston as second stage coupled with a force loop to the pilot stage, and a cartridge valve as main stage, 


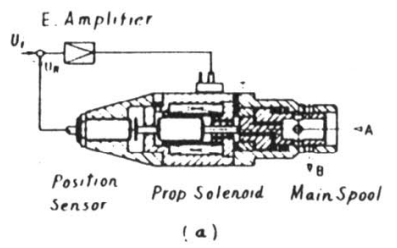

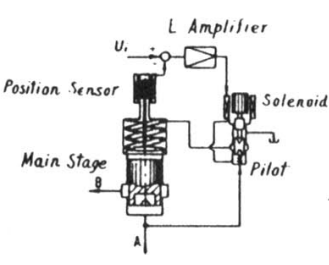

(c)

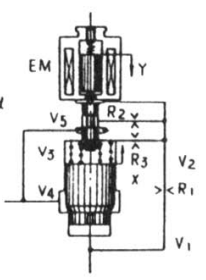

(b)
Fig.24 Pilot proportional throttling valve

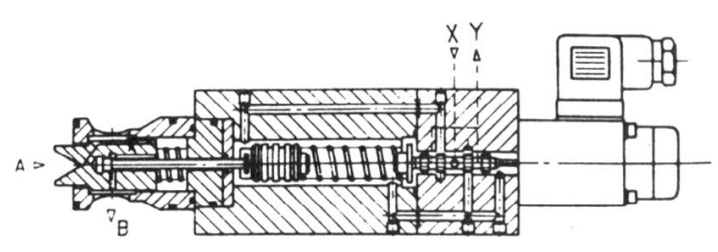

Fig.25 Three stages throttling valve

which is coupled with the stock of the second stage as a positioning servo system.

\section{Proportional flowrate regulator}

A traditional flow regulating valve is composed of a throttling valve with a single stage pressure-difference compensator. Because of the influence of the flow force acting on the compensator, a noticeable error of the valve's flowrate responsing to a given input signal appears . Making the use of a pilot-operated compensator, the constant pressure-difference behavior can be improved, and then the satisfied characteristics of the constant flowrate can be achieved (Fig.26).

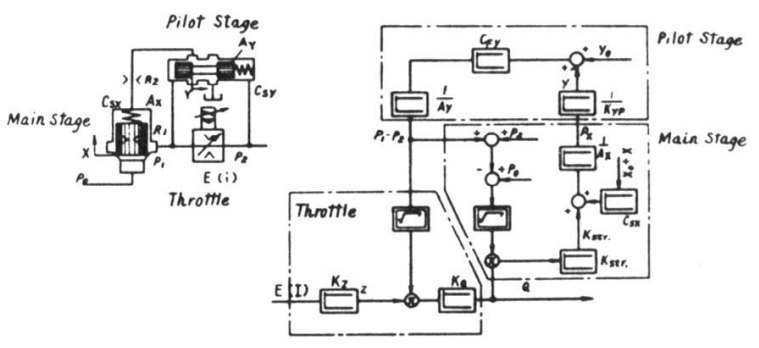

Fig.26 Flow valve with pressure compensator

The other way (see Fig.27) to improve the characteristics of proportional flowrate valve is to combine a proportional throttling valve with a 2-way-cartridge flowrate-sensor, which is used as a feedback unit by translating the flowrate into
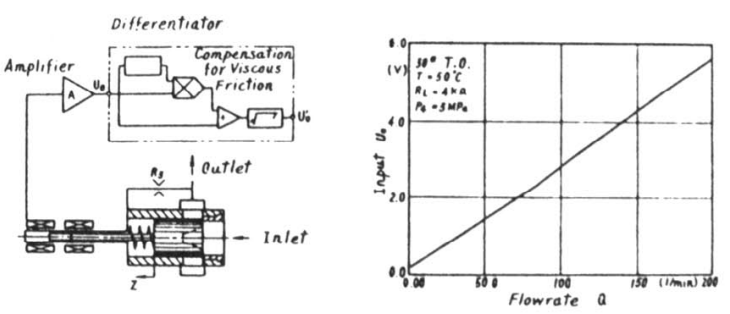

Fig. 27 2-way-cartridge flow sensor

the displacement proportionally. And by using a spring or a displacement sensor, flowrate feedback schemes of flowratedisplacement-force or the flowrate-displacement-electricity feedback can be realized, as is shown is figure 28. This kind of valve has good constant-flowrate and dynamic characteristics (figure 29).

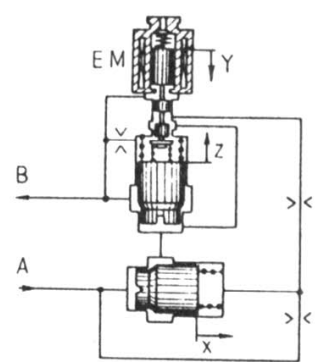

(a)

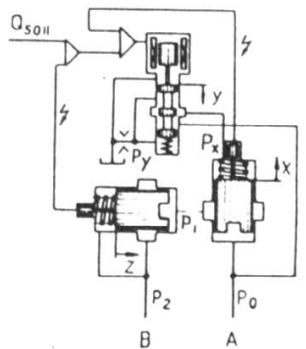

(b)
Fig. 28 Closed control flow valve
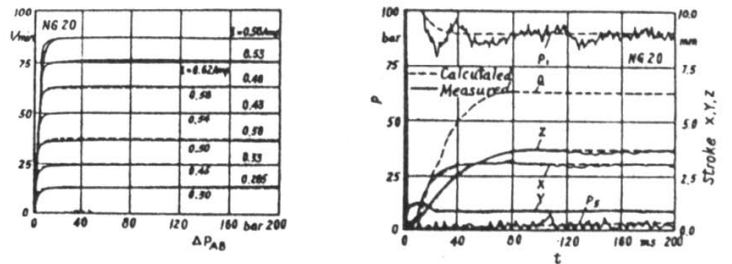

Fig.29 Characteristics of closed control flow valve

\section{CONCLUSION AND FORECAST}

After 20 years' development, proportional-cartridge technique is more and more ripened. The technique possesses the following characters:

--- Favorable reliability, robustness, energy-saving and low-costing

-- With standard mounting plate and exchangeable with traditional valves

--- Robust E-M convertor

--- Functions covering pressure, flowrate and throttling regulation

-- 2-way- and 3-way-cartridge construction 
The construction of a proportional valve is similar to that of a traditional valve, but its performance is close to that of a servo valve. The electro-hydraulic proportional technique functions as an interface between high-power fluid power transmission \& control and electronics. Its development is based on the development of electronics, micro-computer, sensor and material science.

A PWM-concept pilot stage may be as a new effective method to get a more excellent proportional valve which has advantages of insensitive to dirty of oil, energy-saving and lower-costing. But further study should be done to longen its running-life.

\section{REFERENCES}

(1). Lu Yong Xiang, Advanced Achievements of Cartridge Proportional Valves in the Recent Research Work, Proceedings of International Conference on Fluid Power Transmission and Control, Vol. 1, Sept. 1985, Hangzhou, China.

(2). W. Backe', Design Systematics and Performance of Cartridge Valve Con- trols, Proceedings of the International Conference on Fluid Power, March 24-26 1987, Tampere, Finland.

(3). Kai-Yuan Yu, Da-Hong Hu \& Yong-Xiang $\mathrm{Lu}$, Development and Research of a Pilot Proportional Pressure Reducing Valve with New Concepts, Proceedings of the 8th International Symposium on Fluid Power, BHRA April 1987, Birmingham, England.

(4). Z. T. Fung, Lu Yong Xiang, Study on High Pressure Dynamic Flowmeter, Hydraulics \& Pneumatics, No.2, 1987 (in Chinese).

(5). Lu Yong Xiang, Qiu M. X., Wu G. M. \& Huang Y. C., Research and Development of Cartridge Type-3way ElectroHydraulic Proportional Direction Control Valves, Hydraulics \& Pneumatics, No. 6, 1987 (in Chinese).

(6). Yu Kai-Yuan, Research on Performance Optimization of Throttling Control Type Electro-Hydraulic Pressure Control Components, Doctoral Thesis of Zhejiang University, China (in Chinese). 